position and general trends in the industry as a supplier of solid, liquid and gaseous fuels. There is a movement for gas works to pass into the control of holding companies, a process which has led at times to increased efficiency and a reduction in prices to the consumer. Mr. Bennett indicated the dangers to be feared where undertakings were bought at inflated prices, owing to the availability of cheap money, and where the motive force was financial opportunism irrespective of public good. In some countries, organisations have been established for the official testing and certification of gas appliances. Mr. S. Lacey and Mr. C. A. Masterman contended that such a movement could bring no advantage in Great Britain, where the safety and efficiency of gas ap. paratus already exceeds that current in other countries. Mr. W. L. Boon described the rapid advance of gas coke in public favour for domestic purposes. The development of the gravity feed boiler has resulted in coke displacing oil firing of central heating installations. With these boilers, uniform conditions can be maintained automatically, with attendance once in $\mathbf{2 4}$ hours, at a very low fuel cost. Open coke grates are increasing in popularity and already some 70,000 have been installed in London alone.

\section{Flock of Birds Mistaken for Sea-Serpent}

LieUt. A. J. Совнам, R.N., sends us an account of a flock of low-flying birds being mistaken for a sea-serpent. Similar observations have been made before, but it is worth while to put Lieut. Cobham's notes on record. On March 14, 1935, H.M.S. Electra was 100 miles S.W. of C. Spartel (North Africa). At about 17.30 G.M.T., weather being fine and visibility a maximum, Lieut. Cobham was on the bridge with a midshipman and a signalman. Suddenly to the westward, about 200 yards off, what seemed to be a sea-serpent was seen, travelling at about 30 knots on a slightly divergent course. "It had a small head, on the surface, creating a bow-wave, and behind, at intervals of approximately 12 feet, there were four humps, each with a bow-wave. Every 20 seconds or so the beast submerged for a few moments. Inspection with binoculars showed the phenomenon to be a flock of small birds of the guillemot family (Alle alle or Fratercula arctica). They were flying in five ' $V$ '-formations, skimming so closely over the water that from time to time they were hidden by a swell. The light, due to a heat haze, was peculiar. The sea, to the westward, appeared to be an oily grey colour, against which the birds showed black. All three of us had the same impression on sighting, and so 'real' was the appearance that after establishing the truth with binoculars, the birds still looked exactly like a sea-serpent when seen with the naked eye."

\section{Avon Biological Research}

THE annual report of the biological research which is being carried out on the River Avon at Southampton in association with the University College there gives an account of the varied lines of work pursued in the second year of this scheme (Southampton: University College. $2 s, 6 d$.). The general condition of the coarse fish in the area is described, with a special note on the incidence of 'black spot' disease among them. Methods are being sought for checking the loss of fish in mill-races, in the flooding of water-meadows, and by poisoning from decaying masses of weed. The use of green light has been tried to deter fish from entering dangerous waters, as well as a revolving fish screen which automatically keeps itself free from debris. Preliminary experiments have been made on the hatching and rearing of salmon and trout under natural and artificial conditions, and the resulting yield and condition of young fish were determined. The work was seriously hampered throughout by the drought conditions of $1933-34$.

\section{National Institute of Agricultural Botany}

Tre fifteenth annual report (1933-34) of the National Institute of Agricultural Botany, Cambridge, shows that continued progress has been made in all departments. An important change in the stations at which crop testing is carried out took place in the autumn of 1934, when a new centre was established at Askham Bryan near York, in place of that at Good Easter, Essex, which was closed down. The results at the latter station had proved so similar to those at Cambridge, that it seemed more valuable to extend the Institute's activities in a northward direction. Two new winter wheats from the Cambridge University Plant Breeding Institute were tested $(162 / 8 / 1 E$, and $\mathrm{W} .70 A)$ and gave very promising results, while 'Resistance', the new winter oat which had proved so outstanding in former trials, was put on the market for distribution. Continued progress is recorded in the work of the Official Seed Testing Station, 29,487 samples being dealt with during the year under review. With regard to the activities of the Potato Testing Station at Ormskirk, eighty-seven entries were received for the official immunity trials, and all but three of these remained free from wart disease in the field. It is noteworthy that, with the exception of three varieties known to be duplicated, all the new varieties entered for the trials proved to be distinct. This is a striking tribute to the way in which the Potato Synonym Committee has been able to check the practice of distributing old varieties under new names and at an enhanced price.

\section{Report of the Development Commissioners}

THE twenty-fourth report $(1933-34)$ of the Development Commissioners which has just been published (London : H.M. Stationery Office. 2s. net) deals mainly with the various purposes for which advances from the fund were made to assist agriculture, rural economy and fisheries. In general, the allocation of grants was very similar to that in the previous year, but although no actual payments were made, arrangements were completed whereby the work at certain British institutes, hitherto financed by the Empire Marketing Board, could be continued. 